\section{Nomenclature}

a $\quad=$ specific surface area of particles

$a_{m f}=$ specific surface area of naphthalene particles

$B \quad=$ coefficient of Eq.(4)

$C_{b} \quad=$ concentration of naphthalene gas in bubble phase

$C_{\text {ea1 }}=$ calculated concentration of naphthalene gas at the outlet gas

$C_{\mathrm{Ob}}=$ measured concentration of naphthalene gas at the outlet gas

$C_{\mathrm{s}} \quad=$ saturated concentration of naphthalene gas

$D=$ diffusion coefficient

$D_{B} \quad=$ bubble size in the bed

$D_{p} \quad \quad=$ average particle size

$F_{o} \quad=$ gas interchange coefficient

$f \quad=$ the volume ratio of naphthalene particle to glass beads

$g \quad=$ gravitational acceletation

$k_{f} \quad=$ gas-particle mass transfer coefficient in bubble phase

$L \quad=$ expanded bed height

$L_{m f} \quad=$ bed height at the minimum fluidization gas velocity

$Q \quad=$ volume flow rate of the secondary air

$Q_{m f} \quad=$ volume flow rate of the primary air

$S=$ cross sectional area

$r_{B} \quad=$ bubble radius

$r_{c, \text { eff }}=$ effective cloud raduis

$r_{c, \text { max }}=$ maximum cloud radius

$U \quad=$ superficial gas velocity

$U_{b} \quad=$ bubble rising velocity
$U_{b b} \quad=$ bubble rising velocity based on fixed axis

$\bar{U}_{b b} \quad=$ average bubble rising velocity based on fixed axis

$[\mathrm{cm} / \mathrm{sec}]$

$[1 / \mathrm{cm}] \quad U_{m f}=$ the minimum fluidization gas velocity

$[1 / \mathrm{cm}] \quad U_{m f}=$ the minimum fluidization gas velocity

$[\mathrm{cm} / \mathrm{sec}]$

$[1 / \mathrm{cm}] \quad V_{b} \quad=$ volume of single gas bubble in the bed

$\left[\mathrm{cm}^{1 / 2}\right]$

$V$
$Z$

$=$ volume flow rate of gas per unit nozzle

$=$ distance from the gas inlet nozzles

$[\mathrm{cm} / \mathrm{sec}]$

$[\mathrm{cc} / \mathrm{sec}]$

$[\mathrm{cm}]$

$[\mathrm{g} \cdot \mathrm{mole} / \mathrm{cc}]$

$[\mathrm{g} \cdot \mathrm{mole} / \mathrm{cc}]$

$[\mathrm{g} \cdot \mathrm{mole} / \mathrm{cc}]$

gas

$[\mathrm{g} \cdot \mathrm{mole} / \mathrm{cc}]$

$\left[\mathrm{cm}^{2} / \mathrm{sec}\right]$

$[\mathrm{cm}]$

$[\mathrm{cm}]$

$[1 / \mathrm{sec}]$

$\alpha \quad=$ the ratio of cloud volume to bubble volume

$\varepsilon_{m f}=$ void fraction of fluidized bed at $U_{m f}$

$\theta \quad=$ angle measured round bubble

$\rho \quad=$ density of gas

$\mu \quad=$ viscosity of gas

$[-]$

$[-]$

$[-]$

$[\mathrm{g} / \mathrm{cc}]$

$[\mathrm{g} / \mathrm{cm} \cdot \mathrm{sec}]$

\section{Literature Cited}

1) Davison, J. F. and D. Harrison: "Fluidized Particles", Cambridge Unversity Press (1963)

2) Harrison, D. and L. S. Leung: Trans. Inst. Chem. Engrs., 39, 409 (1961)

[cm/sec 2$]$ 3) Kato, K. H. Kubota and C. Y. Wen: Chem. Eng. Prog., Symp. Series 105, 66, $87(1970)$

[cm/sec] 4) Kato, K. and C. Y. Wen: Chem. Eng. Sci., 24, 1351 (1969)

[cm] 5) Kobayashi, H., F. Arai and T. Sunagawa: Kagaku Kōgaku, 31, 239 (1967)

[cm] 6) Kunii, D. and O. Levenspiel: Ind. Eng. Chem., Fund., 7, 446 (1968)

7) Murray, J. D.: Chem. Eng. Progr., Symp. Series, 62, 71 (1966)

$[\mathrm{cc} / \mathrm{sec}]$

$[\mathrm{cc} / \mathrm{sec}]$

$[\mathrm{cc} / \mathrm{sec}]$

$[\mathrm{cm}]$

$[\mathrm{cm}]$

$[\mathrm{cm}]$

[cm/sec] $[\mathrm{cm} / \mathrm{sec}]$

8) Ranz, W. E. and W. R. Marshall: J. Chem. Eng. Progr., 48, $173(1952)$

9) Rowe, P. N., B. A. Partridge and E. Lyall: Chem. Eng. Sci., 19, 973 (1964)

10) Wakabayashi, T. and D. Kunii: J. Chem. Eng. Japan, 4, No. 3 $226(1971)$

\title{
CATALYTIC CRACKING OF METHYLCYCLOHEXANE OVER SILICA ALUMINA CATALYST IN GAS FLUIDIZED BED*
}

\author{
Setsuji TONe, Hiroyasu SEKO**, Hisao MaRUyama*** \\ and Tsutao OTAKE \\ Department of Chemical Engineering, Faculty of Engineering Science, \\ Osaka University, Osaka
}

\begin{abstract}
This paper presents a simulation model to predict the reaction performance of a fluidized bed from the operating conditions. The simulation model was derived from the observation of bubble behavior, and was developed in a form which can elucidate the conversion and selectivity with catalyst fouling. The model was applied to methylcyclohexane cracking data, and unknown parameters in the model were estimated by a non-linear regression technique. It was confirmed that the model is applicable to the performance of a fluidized bed reactor.
\end{abstract}

\section{Introduction}

The fluidized bed reactor is widely applied to catalytic reactions because of the advantages of uniform temperature, but there is low conversion of chemical

* Received on May 26, 1973

Presented at the 5th Autumn Meeting of The Soc. of Chem.

Engrs., Japan, at Osaka, Oct. 6, 1971

** Tanabe Seiyaku Co., Ltd.

*** Kanebo Co., Ltd.

T560 大阪府豊中市待兼山町1-1

大阪大学基礎工学部化学工学科 東稔節治 reaction, mainly caused by the gas by-passing through the bed. Considerable evidence for the two-phase model has appeared in the literature ${ }^{1,7,10,13)}$, and it is known that gas interchange between the two phases influences conversion and selectivity. Rowe et al.16) proposed a model in which a rising bubble is surrounded by a cloud of circulating gas, and some interchange occurs between the cloud and dense phases. Kobayashi et al. ${ }^{9)}$ reported a two-phase model describing the gas interchange between the cloud phase involving a cloud-wake overlap and dense phase. Fryer and Potter ${ }^{2)}$, and Kunii and Levenspiel ${ }^{10)}$ ad- 
vanced a model involving an upward flow of solids with the bubbles. Furthermore, Kunii et al. ${ }^{10)}$ advanced a correlation of successive gas interchange among bubbles cloud-wake and dense phase according to the Davidson and Harrison theory ${ }^{1}$ and the Higbie-type penetration model ${ }^{15)}$. Despite numerous studies, there has been no unequivocal model to predict the performance of chemical reaction in the fluidized bed.

The purpose of this study is to give the formulation of an adequate model to elucidate the conversion and selectivity of catalytic cracking with catalyst fouling in the fluidized bed reactor. In a recent paper ${ }^{23)}$, the authors proposed a model for the kinetics of methylcyclohexane $(\mathrm{MCH})$ cracking in a fixed bed reactor. In the present study, MCH cracking in the fluidized bed was investigated and bubble behavior was observed. On the basis of the kinetics of $\mathrm{MCH}$ cracking in the fixed-bed reactor, a simulation model based on the bubble behavior was advanced. From this model, unknown parameters such as gas interchange coefficient and cloud-wake volume fraction to bubble volume were evaluated by a nonlinear regression technique, and were studied for the operating conditions.

\section{Experimental}

\subsection{Reagent, experimental apparatus' and cata- lyst}

MCH employed as the sample of cracking reaction was obtained from a commercial source and purified by distillation.

A flow sheet of the experimental apparatus is shown in Fig. 1. Two different sizes of reactors made of quartz tube were used, one of them being $4.51 \mathrm{~cm} \phi \times 40 \mathrm{~cm}$ and the other $5.21 \mathrm{~cm} \phi \times 50 \mathrm{~cm}$. The gas distributor was a sintered porous plate of $-60+80$ mesh fraction of quartz particles.

The cracking catalyst (Shokubai Kasei Co.) used consisted of $75 \mathrm{wt} \%$ silica and $25 \mathrm{wt} \%$ alumina, and was sifted out in the range of $-150+170$ mesh fractions and then calcined in an air stream for 3 hours at $600^{\circ} \mathrm{C}$. The particle density $\left(\rho_{p}\right)$ was $0.836 \mathrm{~g} / \mathrm{cc}$ and bulk density $\left(\rho_{B}\right)$ was $0.475 \mathrm{~g} / \mathrm{cc}$.

For the measurement of temperature of the catalyst bed and the bath of fluidized alumina particles, an alumel-chromel thermocouple was used, as shown in Fig. 1.

\section{2 Measurement of bed expansion and rising bubble size}

The incipient fluidization velocity $\left(u_{m f}\right)$ was observed by measuring pressure drop in the stream of $\mathrm{N}_{2}-\mathrm{MCH}$ mixture at $470^{\circ} \mathrm{C}, 500^{\circ} \mathrm{C}$ and $530^{\circ} \mathrm{C}$.

The bed expansion during fluidization was measured by visual observation through the transparent quartz wall at the same temperature conditions, and the bed height at the incipient fluidizing conditions $\left(L_{m f}\right)$ was also measured.

To study the bubble behavior in the fluidized bed, the bubble frequency was measured by means of a capacitance probe, as illustrated in detail in Fig. 2, at

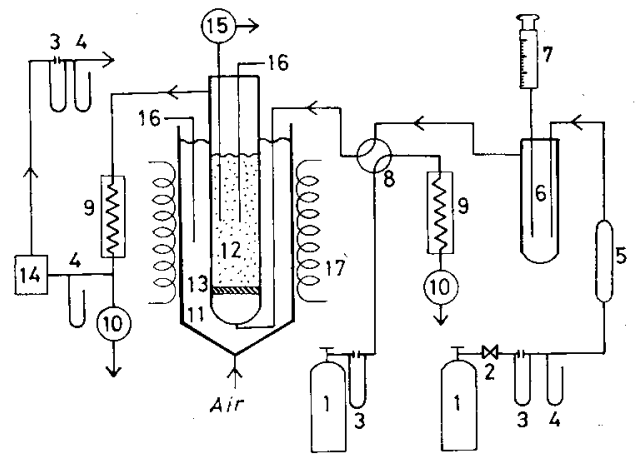
1. nitrogen cylinder
2. needle valve
3. gas flow meter
4. manometer
5. dryer
6. vaporizer
7. micro feeder
8. cock
9. cooler condenser

10. liquid sampler

11. bath of fluidized alumina particles

12. fluidized bed reactor

13. gas distributor

14. gas chromatograph

15. coke sampler

16. thermocouple

17. electric furnace

Fig. 1 Flow sheet of experimental apparatus

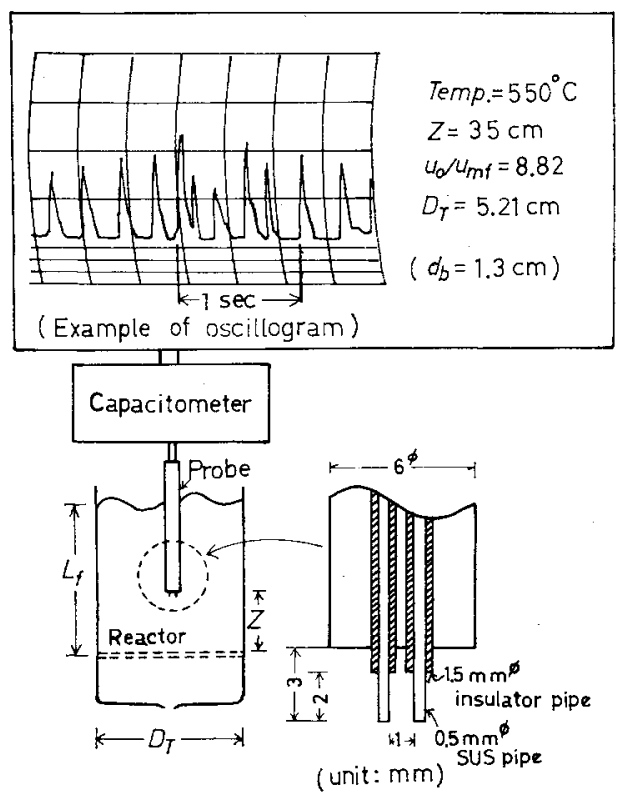

Fig. 2 Electric capacitance probe to measure bubble size

various bed heights and flow rates in the temperature range of $30-650^{\circ} \mathrm{C}$ in both $\mathrm{N}_{2}$ and $\mathrm{N}_{2}-\mathrm{MCH}$ streams. On the other hand, the shape and size of rising bubbles were photographed through the quartz tube wall.

The rate of solid mixing was measured according to Talmor and Benenati ${ }^{21)}$. The bed was prepared in two layers-a layer of coked catalyst (black) above a layer of fresh catalyst (white), and was fluidized with $\mathrm{N}_{2}$ stream at $500^{\circ} \mathrm{C}$. The bed was uniformly mixed after 15 seconds at $3.5 u_{m f}$. It was ascertained that the fluidized bed behaved as completely mixed state.

1.3 Measurement of MCH conversion and product yield in fluidized bed cracking

The reactor with passage of nitrogen gas was placed in the bath of fluidized alumina particles used as thermomedium. After the temperature of catalyst bed reached equilibrium, the stream of $\mathrm{N}_{2}-\mathrm{MCH}$ mixture 


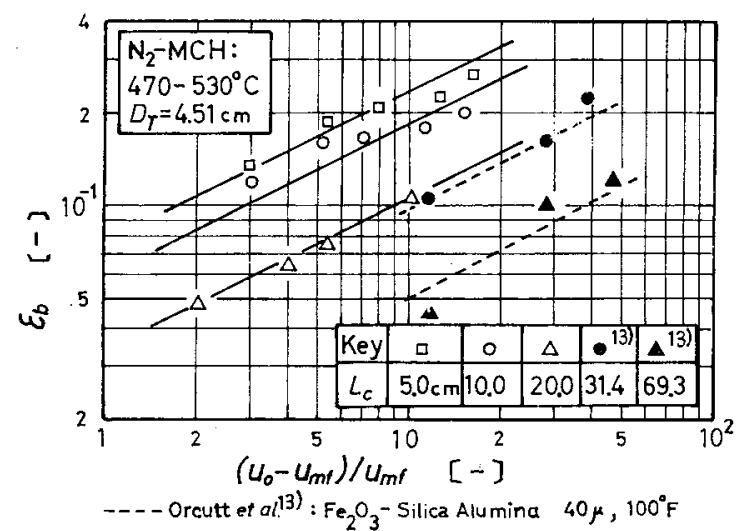

Fig. 3 Bubble volume fraction vs. $\left(u_{o}-u_{m f}\right) / u_{m f}$

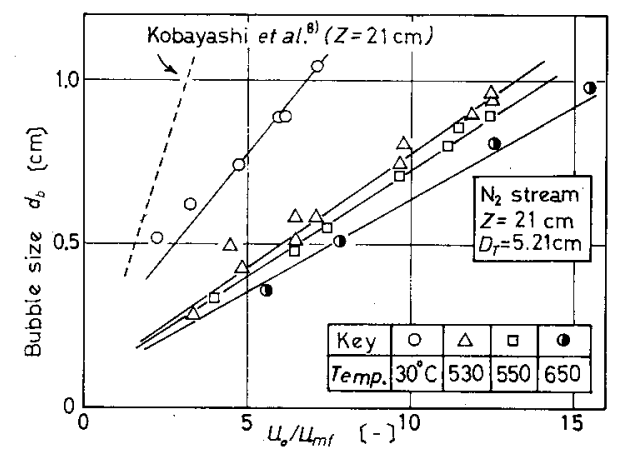

Fig. 4 Bubble size vs. $u_{o} / u_{m f}$ with parameter of temperature

( $50 \mathrm{~mol} \% \mathrm{MCH}$ ) was passed through the reactor to start the cracking reaction. The feed $\mathrm{MCH}$ flow rate was controlled by microfeeder. The exit products were condensed through a cooler condenser, and the condensed mixture was subjected to gas chromatographic analysis using a DC-550 column. Uncondensed gaseous products were led to the gas chromatograph directly and analyzed using an alumina + squalane column. The difference of gas density between inlet and outlet was found to be negligible.

The coked catalyst was withdrawn by sucking, and the weight of coke formed on the catalyst was measured by means of a thermanogravimetric balance. The experimental conditions are summarized in Table 3.

\section{Experimental Results}

\section{1 Incipient fluidization velocity and bed expansion}

The value of $u_{m f}$ gradually decreased with increasing temperature, as shown in Table 3 , but a bed voidage at the incipient fluidization $\left(\varepsilon_{m f}\right)$ kept a uniform value at various bed heights and temperatures. The bubble volume fraction $\left(\varepsilon_{b}\right)$ was calculated based on the measurement of $L_{m f}$ and $L_{f}$ in the $\mathrm{N}_{2}-\mathrm{MCH}$ stream, and is represented by Eq. (1) as a result of the slope of these linear plots as shown in Fig. 3.

$$
\begin{array}{r}
\varepsilon_{b}=\frac{L_{f}-L_{m f}}{L_{f}}=0.115\left(\frac{u_{o}-u_{m f}}{u_{m f}}\right){ }^{0.5} L_{c}^{-0.5} \\
\text { (unit: CGS) }
\end{array}
$$

The results were compared with the value of $\varepsilon_{b}$ for an

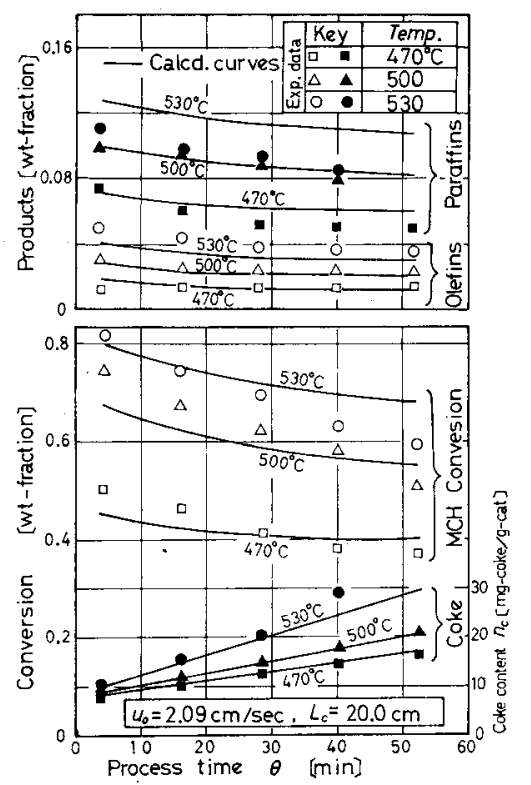

Fig. 5 An example of plots of conversion and yield vs. process time

ozone decomposition in a fluidized bed according to Orcutt et al. ${ }^{13)}$.

\section{2 Determination of bubble size}

Assuming that the bubble frequency $(n)$ has a uniform value across any horizontal plane, the bubble size $\left(d_{b}\right)$ would be evaluated according to the Kunii and Levenspiel formula ${ }^{10)}$, i.e.,

$$
d_{b}=\frac{1.5 u_{b}}{n} \cdot \frac{u_{o}-u_{m f}}{u_{b}-u_{m f}} \simeq \frac{1.5}{n}\left(u_{o}-u_{m f}\right)
$$

Bubble frequency measured with $\mathrm{N}_{2}-\mathrm{MCH}$ stream closed to that of $\mathrm{N}_{2}$ stream only, and the $d_{b}$ calculated from bubble frequency agreed reasonably well with that of the photograph. The values of $d_{b}$ decrease with increasing temperature, as shown in Fig. 4, and were found about one half the value of the empirical formula of Kobayashi et $a l .^{8}$ ) at room temperature, where the ratio of wake volume to bubble volume was taken to be 0.47 according to the data (glass sphere) of Rowe and Partridge ${ }^{17)}$. These facts may be illustrated with the drop in viscosity of the fluidized bed according to $\mathrm{Mii}$ et al. ${ }^{12)}$. The $d_{b}$ was also found to vary linearly with the axial distance $(\boldsymbol{Z})$ from a gas distributor. As a result, the empirical formula of $d_{b}$ is approximately expressed by Eq. (3), obtained from Fig. 4.

$$
d_{b}=\frac{0.00142 Z+0.0233}{\left(T \times 10^{-3}\right)^{1.21}} \cdot\left(\frac{u_{o}}{u_{m f}}\right)+0.08
$$

The difference in respective $\varepsilon_{b}$ and $d_{b}$ for each different size of reactor was found to be negligible.

\section{3 MCH conversion and product yield in fluidized bed}

The products of $\mathrm{MCH}$ cracking in the fluidized bed were hydrogen, $\mathrm{C}_{1}-\mathrm{C}_{6}$ hydrocarbons, aromatic compounds, etc. The main products were propane, propylene, butanes and butenes, and were similar to those in a fixed-bed reactor ${ }^{23)}$. 

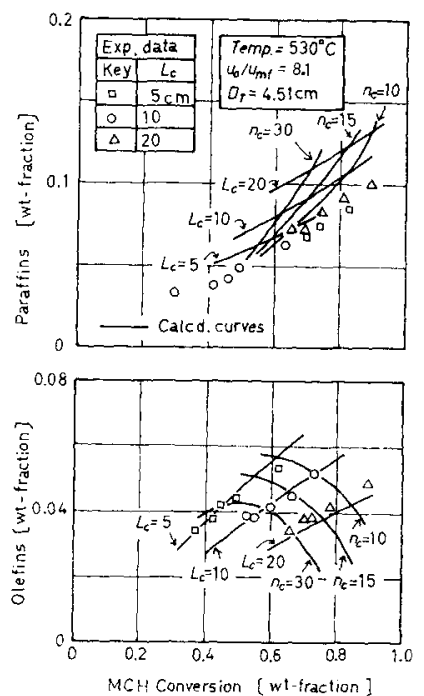

Fig. 6 An example of plots of olefins and paraffins vs. MCH conversion with parameter of static bed height
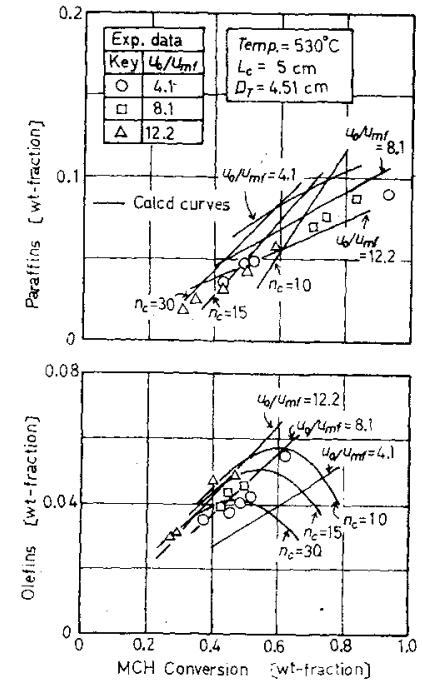

Fig. 7 An example of plots of olefins and paraffins vs. MCH conversion with parameter of gas flow rate

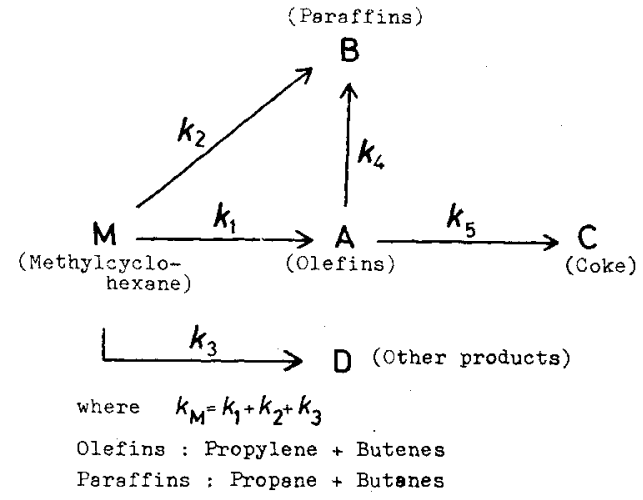

Fig. 8 MCH cracking model 23 )

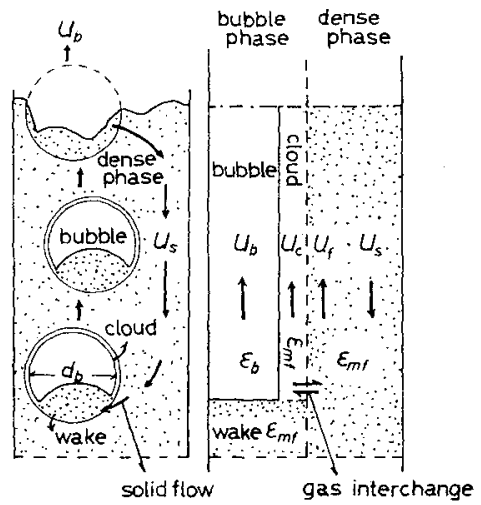

gas interchange

Fig. 9 Model to account for gas interchange between bubble phase and dense phase

Table 1 Reaction rate constants and parameters for a small-scale fixed bed 23 )

$$
\begin{aligned}
& k_{M}=\exp (25.8-38500 / R T) \phi \\
& k_{1}=\exp (24.8-39100 / R T) \phi \\
& k_{2}=\exp (25.2-42300 / R T) \phi \\
& k_{4}=\exp (-5.15+7000 / R T) \\
& k_{5}=\exp (-5.87+3360 / R T) \\
& \alpha=\exp (10.5-18600 / R T) \\
& \phi=1 /\left(1+\alpha n_{e}\right)
\end{aligned}
$$

olefins may be attained by adjusting the operating conditions.

\section{Mathematical Formulation of Model}

\section{1 Kinetic model and two-phase model}

In the previous work ${ }^{23)}$, the reaction mechanism of $\mathrm{MCH}$ cracking was investigated in a small-scale fixedbed reactor. The kinetics was reported by the reaction model shown in Fig. 8. The rate constant of each step and an activity factor indicating catalyst fouling are given in Table 1.

In recent research, bubble behavior in the fluidized bed was made clear theoretically and experimentally by Davidson and Harrison ${ }^{1)}$, Rowe et al. ${ }^{16)}$ and Kunii and Levenspiel ${ }^{10)}$. However, these rigorous mathematical models may be impracticable for the simulation of such a complicated reaction system as MCH cracking with catalyst fouling as shown in Fig. $8^{23)}$.

For the development of the simulation model for the fluidized bed based on bubble behavior, the following simplifying assumptions are made:

1) The fluidized bed consists of the bubble phase with wake solids and the dense phase, in which interstitial gas flows at incipient state.

2) The bubble phase consists of the bubble and wake surrounded by a spherical cloud. The cloud volume is negligibly small compared with the wake volume, and the solids in the cloud are ignored. The cloud volume, therefore, is lumped together with the wake volume. This assumption ${ }^{2,10,11)}$ is supported where $u_{o} / u_{m f}$ is large, as shown in Table 3.

3) Finite interchange of gases occurs between the bubble and dense phases, and the main transfer resistance exists between cloud boundary and dense phase.

4) The gas composition in the bubble with cloud-wake is uniform.

5) The average of size and velocity of the rising bubbles are given over the whole bed.

6) The voidage distribution is uniform over the whole bed.

7) The voidage in the cloud-wake is equal to that of incipient bed.

A sketch of the bubble model is illustrated in Fig. 9. 3.1.1 Gas velocity According to the Kunii and Levenspiel hypothesis ${ }^{10)}$, the upward velocity of gas 
through the dense phase $\left(u_{e}\right)$ is given by subtracting the downward velocity of solids in dense phase $\left(u_{s}\right)$ from the upward velocity of the gas at incipient state $\left(u_{f}\right)$.

$$
u_{e}=u_{f}-u_{s}=\frac{u_{m f}}{\varepsilon_{m f}}-u_{s}
$$

The rising velocity of cloud-wake $\left(u_{c}\right)$ is assumed to be equal to that of rising bubble $\left(u_{b}\right)$.

Consequently, $u_{o}$ is shown by Eq. (12) from the summation of gas flow in each phase.

$$
\begin{gathered}
u_{o}=\varepsilon_{b} u_{b}\left(1+\delta_{w} \varepsilon_{m f}\right)+\varepsilon_{m f}\left\{1-\varepsilon_{b}\left(1+\delta_{w}\right)\right\} u_{e} \\
\text { (cloud-wake and bubble phase) (dense phase) }
\end{gathered}
$$

where $\delta_{w}$ can be defined as Eq. (13) in this study.

$$
\delta_{w}=\frac{\text { volume of cloud-wake around a bubble }}{\text { volume of a bubble }} .
$$

The amount of the downward flowing solids in the dense phase is equal to that of the upflowing solids in the cloud-wake, and the relation is given by Eq.(14).

$$
\left\{1-\varepsilon_{b}\left(1+\delta_{w}\right)\right\} u_{s}=\varepsilon_{b} \delta_{w} u_{b}
$$

Combining Eqs.(11) and (12) with Eq.(14),

$$
u_{o}=\varepsilon_{b} u_{b}+\left\{1-\varepsilon_{b}\left(1+\delta_{w}\right)\right\} u_{m f}
$$

if $u_{o} \gg \varepsilon_{b}\left(1+\delta_{w}\right) u_{m f}$, the average velocity of rising bubbles is approximated by Eq. (16).

$$
u_{b}=\frac{u_{o}-u_{m f}+\varepsilon_{b}\left(1+\delta_{w}\right) u_{m f}}{\varepsilon_{b}} \simeq \frac{u_{o}-u_{m f}}{\varepsilon_{b}}
$$

3. 1.2 Material balance Two assumptions are made to derive a material balance for each component.

1) The gas interchange coefficient between bubble and dense phases per unit of bubble volume is uniform through the bed.

2) The cracking system is in a pseudo-steady state because the individual product traverses the bed so quickly relative to catalyst fouling at a definite process time.

With these two assumptions, we may then derive the following simplified ordinary differential equations for an element of the bed height $(d Z)$ and of the unit crosssectional area in both phases.

i) $\operatorname{MCH}(M)$ balance

For the bubble phase,

$$
-u_{1} \frac{d C_{M c}}{d Z}=K_{c M}\left(C_{M c}-C_{M e}\right)+k_{r M} \gamma_{c} C_{M c}
$$

For the dense phase,

$$
-u_{2} \frac{d C_{M e}}{d Z}=K_{c M}\left(C_{M e}-C_{M e}\right)+k_{r M} \gamma_{e} C_{M e}
$$

ii) Olefins $(A)$ balance

For the bubble phase,

$$
\begin{aligned}
-u_{1} \frac{d C_{A c}}{d Z}=K_{c A}\left(C_{A c}-C_{A e}\right) & +\gamma_{c}\left\{-k_{r 1} C_{M e}\right. \\
& \left.+\left(k_{r 4}+k_{r 5}\right) C_{A c}\right\}
\end{aligned}
$$

For the dense phase,

$$
\begin{aligned}
-u_{2} \frac{d C_{A e}}{d Z}= & K_{C A}\left(C_{A e}-C_{A c}\right) \\
& +\gamma_{e}\left\{-k_{r 1} C_{M e}+\left(k_{r 4}+k_{r 5}\right) C_{A e}\right\}
\end{aligned}
$$

3) Paraffins $(B)$ balance

For the bubble phase,

$$
-u_{1} \frac{d C_{B c}}{d Z}=K_{c B}\left(C_{B c}-C_{B e}\right)-\gamma_{c}\left(k_{r 2} C_{M c}+k_{r 4} C_{A c}\right)
$$

For the dense phase,

$$
-u_{2} \frac{d C_{B e}}{d Z}=K_{c B}\left(C_{B e}-C_{B c}\right)-\gamma_{e}\left(k_{r 2} C_{M e}+k_{r 4} C_{A e}\right)
$$

where

$$
u_{1}=u_{b}\left(1+\delta_{w} \varepsilon_{m f}\right) \quad(23), \quad u_{2}=\left\{1-\varepsilon_{b}\left(1+\delta_{w}\right)\right\} \cdot \frac{u_{e} \varepsilon_{m f}}{\varepsilon_{b}}
$$

$\gamma_{c}=\left(1-\varepsilon_{m f}\right) \delta_{w}$

(25), $\gamma_{e}=\left(1-\varepsilon_{m f}\right)\left\{1-\varepsilon_{b}\left(1+\delta_{w}\right)\right\} / \varepsilon_{b}$

4) Coke formation

Assuming that the solids within the bed are completely mixed, the rate of coke formation per unit weight of catalyst is written as

$$
\frac{d n_{c}}{d \theta}=k_{r 5}\left(\nu_{1} \gamma_{c} \overline{C_{A c}}+\nu_{2} \gamma_{e} \overline{C_{A e}}\right)
$$

where

$$
\overline{C_{A c}}=\frac{1}{L_{f}} \int_{0}^{L_{f}} C_{A c} d Z, \quad \overline{C_{A e}}=\frac{1}{L_{f}} \int_{0}^{L_{f}} C_{A e} d Z
$$

$\nu_{1}$ and $\nu_{2}$ are the conversion factors for the coke formation based on the process time, namely,

$$
\begin{aligned}
& \nu_{1}=1000 L_{f} f_{M} /\left(u_{1} W\right) \\
& \nu_{2}=1000 L_{f} f_{M} \varepsilon_{b} /\left[u_{m f}\left\{1-\varepsilon_{b}\left(1+\delta_{w}\right)\right\} W\right]
\end{aligned}
$$

Boundary conditions are:

i) at $Z=0$, for $\theta \geq 0, C_{M j}=1.0, C_{A j}=C_{B j}=0(j=c, e)$

ii) for $Z>0$, at $\theta=0, n_{c}=0$

\section{2 Evaluation of model parameters}

Before applying the mathematical model to the experimental data, the model could be further simplified. It is said that the upward velocity of gas in the dense phase $\left(u_{e}\right)$ is negligibly small where $u_{o} / u_{m f}$ is large ${ }^{7,10}$. By using Eqs.(11), (14) and (15), $u_{e} / u_{m f}$ can be expressed as

$$
\frac{u_{e}}{u_{m f}}=\frac{1}{\varepsilon_{m f}}-\frac{\delta_{w}\left(u_{o}-u_{m f}\right)}{\left[1-\varepsilon_{b}\left(1+\delta_{w}\right)\right] u_{m f}}
$$

Under the experimental conditions (i.e., $u_{o} / u_{m f}$ being 3.5-12.1) as shown in Table 3, Eq.(33) gives $u_{e} / u_{m f} \simeq 0$ for $u_{o} / u_{m f}=3.8, u_{e} / u_{m f}=-0.05--0.11$ for $u_{o} / u_{m f}=7.0-12.1$, from the assumption of $\delta_{w}$ being 0.5 .

From the calculations, it is found that our experimental conditions are almost in the region in which downflow of gas in the dense phase takes place, and that the values of $u_{e}$ are negligibly smaller than those of $u_{m f}$. It is therefore reasonable to assume $u_{e}$ as zero under the experimental conditions as shown in Table 3.

To evaluate the model parameters of $K_{c i}(i=M, A)$ 
and $\delta_{w}$, six simultaneous differential equations from Eq. (17) to Eq. (22) could be solved analytically based on $u_{e}$ being zero, and the solutions are given in Table 2, where the values of $C_{i}\left(L_{f}\right)$ represent the product concentrations at the top of the bed and are considered to be equal to those of bubble phase.

The evaluation procedures were performed as follows. At first, the values of $C_{i}\left(L_{f}\right)$ in Table 2 were calculated using the coke content corresponding to $\theta=4 \mathrm{~min}$, and the rate of coke formation in a

Table 2 Solutions of Eqs. (17)-(22) at $u_{e}=0$

1) $\mathrm{MCH}$

2) Olefins

$$
C_{M}\left(L_{f}\right)=\exp \left(-D L_{f}\right)
$$

$$
C_{A}\left(L_{f}\right)=P\left\{\exp \left(-D L_{f}\right)-\exp \left(-\frac{F L_{f}}{u_{1}}\right)\right\}
$$

3) Paraffins

$C_{B}\left(L_{f}\right)=\frac{(Q+S P)}{D u_{1}}\left\{1-\exp \left(-D L_{f}\right)\right\}-\frac{S P}{P}\left\{1-\exp \left(-\frac{F L_{f}}{u_{1}}\right)\right\}$

where

$$
\begin{aligned}
& D=\frac{k_{r M}\left(\gamma_{e} E+\gamma_{c}\right)}{u_{1}}, \quad E=\frac{K_{c M}}{K_{c M}+\gamma_{e} k_{r M}} \\
& F=\frac{K_{c A}\left(k_{r 4}+k_{r 5}\right)\left(\gamma_{c}+\gamma_{e}\right)+\gamma_{c} \gamma_{e}\left(k_{r 4}+k_{r 5}\right)^{2}}{K_{c A}+\gamma_{e}\left(k_{r_{4}}+k_{r 5}\right)} \\
& G=\gamma_{e} k_{r_{1}}+\frac{\gamma_{e} K_{c A} k_{r_{1}} E}{K_{c A}+\gamma_{e}\left(k_{r 4}+k_{r 5}\right)} \\
& P=\frac{G}{F-D u_{1}} \\
& Q=\gamma_{e} k_{r 2} E+\gamma_{c} k_{r 2}+\frac{\gamma_{e}^{2} k_{r_{1}} k_{r 4} E}{K_{c A}+\gamma_{e}\left(k_{r_{4}}+k_{r 5}\right)} \\
& S=\gamma_{c} k_{r_{4}}+\frac{\gamma_{e} K_{c A}+k_{r 4}}{K_{c A}+\gamma_{e}\left(k_{r_{4}}+k_{r 5}\right)}
\end{aligned}
$$

definite process time $\left(\Delta n_{c} / \Delta \theta\right)$ was calculated from $\mathrm{Eq}$. (27). Consequently, the coke content corresponding to $\theta+\Delta \theta$ should be shown by $n_{c}+\Delta n_{c}$. These procedures were repeated for the calculation of objective function $(\phi)$ as expressed in Eq. (43) until the final value of process time was reached.

$$
\phi=\sum_{j=1}^{5} \sum_{\substack{i=M, \boldsymbol{A}, B}}^{3} \omega_{i}\left(C_{i, \mathrm{exp}}-C_{i, \mathrm{ca} 1}\right)^{2}+\omega_{c} \sum_{j=1}^{5}\left(n_{c, \exp }-n_{c, \mathrm{ca} 1}\right)^{2}
$$

where the suffix " $i, \exp ^{\prime}$ " and " $i$,cal" are used to denote the experimental and calculated values, respectively; the values of $\omega_{i}$ and $\omega_{c}$ are weighting factors and were chosen to evaluate the $\phi$ exactly for all experimental data as shown in Table 3.

The model parameters can be estimated according to the non-linear regression technique, modifying the method developed by Sobol ${ }^{20)}$. The model parameters evaluated are tabulated in Table 3 .

\section{3 Rearrangement of model parameters with operating conditions}

By considering the bubble velocity and bubble size governing the interchange coefficient, the following relation was derived by dimensional analysis.

\begin{tabular}{|c|c|c|c|c|c|c|c|c|c|c|}
\hline & & Run & $\begin{array}{c}u_{o}^{* * *} \\
{[\mathrm{~cm} / \mathrm{sec}]}\end{array}$ & $\begin{array}{c}L_{c} \\
{[\mathrm{~cm}]}\end{array}$ & $\begin{array}{c}L_{f} \\
{[\mathrm{~cm}]}\end{array}$ & {$[-]$} & $\begin{array}{c}\bar{d}_{b} \\
{[\mathrm{~cm}]}\end{array}$ & $\begin{array}{l}K_{c M} \\
{\left[\sec ^{-1}\right]}\end{array}$ & $\begin{array}{c}K_{c A} \\
{\left[\sec ^{-1}\right]}\end{array}$ & {$[\stackrel{\delta w}{-}]$} \\
\hline Temp. & $=470^{\circ} \mathrm{C}$ & 12 & 1.04 & 5.0 & 7.0 & 0.11 & 0.22 & 0.71 & 1.08 & 0.43 \\
\hline$u_{m f}$ & $=0.300^{*}$ & 13 & 1.04 & 10.0 & 13.6 & 0.10 & 0.24 & 0.71 & 0.87 & 0.55 \\
\hline$D_{G M}$ & $=0.373 * *$ & 14 & 1.04 & 20.0 & 25.8 & 0.05 & 0.29 & 0.86 & 3.16 & 0.53 \\
\hline$D_{G A}$ & $=0.527 * *$ & 19 & 2.09 & 5.0 & 7.8 & 0.20 & 0.37 & 0.34 & 0.46 & 0.53 \\
\hline & $=0.55$ & 20 & 2.09 & 10.0 & 14.7 & 0.16 & 0.42 & 0.23 & 0.13 & 0.43 \\
\hline & & 21 & 2.09 & 20.0 & 26.9 & 0.09 & 0.50 & 0.55 & 0.66 & 0.53 \\
\hline & & 30 & 3.12 & 10.0 & 14.8 & 0.17 & 0.59 & 0.44 & 0.53 & 0.50 \\
\hline & & 28 & 3.12 & 20.0 & 27.8 & 0.11 & 0.72 & 1.76 & 2.09 & 0.50 \\
\hline Temp. & $=500^{\circ} \mathrm{C}$ & 11 & 1.04 & 5.0 & 7.0 & 0.11 & 0.23 & 1.14 & 1.36 & 0.50 \\
\hline$u_{m f}$ & $=0.270^{*}$ & 10 & 1.04 & 10.0 & 13.6 & 0.10 & 0.25 & 0.08 & 0.95 & 0.53 \\
\hline$D_{G M}$ & $=0.386 * *$ & 9 & 1.04 & 20.0 & 25.8 & 0.05 & 0.30 & 1.06 & 2.50 & 0.43 \\
\hline$D_{G A}$ & $=0.546 * *$ & 6 & 2.09 & 5.0 & 7.8 & 0.20 & 0.38 & 0.76 & 0.90 & 0.53 \\
\hline & $=0.55$ & 7 & 2.09 & 10.0 & 14.7 & 0.17 & 0.44 & 0.74 & 0.88 & 0.50 \\
\hline & & 8 & 2.09 & 20.0 & 26.9 & 0.09 & 0.53 & 1.16 & 1.38 & 0.53 \\
\hline & & 17 & 3.12 & 20.0 & 27.4 & 0.11 & 0.76 & 0.68 & 0.30 & 0.45 \\
\hline Temp. & $=530^{\circ} \mathrm{C}$ & 35 & 1.04 & 5.0 & 7.0 & 0.11 & 0.23 & 1.80 & 2.14 & 0.50 \\
\hline$u_{m f}$ & $=0.257^{*}$ & 36 & 1.04 & 10.0 & 13.6 & 0.10 & 0.26 & 0.73 & 0.87 & 0.53 \\
\hline$D_{G M}$ & $=0.438 * *$ & 37 & 1.04 & 20.0 & 25.8 & 0.05 & 0.30 & 1.70 & 1.89 & 0.43 \\
\hline$D_{G A}$ & $=0.620^{*} *$ & 34 & 2.09 & 5.0 & 7.8 & 0.20 & 0.39 & 1.04 & 2.19 & 0.43 \\
\hline \multirow[t]{4}{*}{$\varepsilon_{m f}$} & $=0.55$ & 23 & 2.09 & 10.0 & 14.7 & 0.16 & 0.44 & 1.55 & 1.83 & 0.55 \\
\hline & & 22 & 2.09 & 20.0 & 26.9 & 0.09 & 0.53 & 1.53 & 1.82 & 0.53 \\
\hline & & 31 & 3.12 & 5.0 & 7.9 & 0.21 & 0.56 & 3.29 & 3.91 & 0.55 \\
\hline & & 33 & 3.12 & 20.0 & 27.4 & 0.10 & 0.76 & 1.46 & 0.28 & 0.43 \\
\hline
\end{tabular}

$$
\frac{K_{c i} \overline{d_{b}}}{u_{b}}=\beta_{i}\left(\frac{D_{G i}}{u_{b} \overline{d_{b}}}\right)^{m} \quad(i=M, A)
$$

where $\bar{d}_{b}$ is the average size of bubbles along the bed height and is given by using Eq.(3).

$$
\bar{d}_{b}=\frac{1}{L_{f}} \int_{0}^{L_{f}} d_{b} d Z
$$

where $D_{G i}(i=M, A)$ is the molecular diffusivity in a

Table 3 Experimental conditions and the results of estimated parameters

weighting factors: $\omega_{1}=0.02, \quad \omega_{2}=\omega_{3}=1.0, \quad \omega_{c}=0.00024$

unit: $* \mathrm{~cm} / \mathrm{sec}, * * \mathrm{~cm}^{2} / \mathrm{sec} * * *$ at reaction temperature 


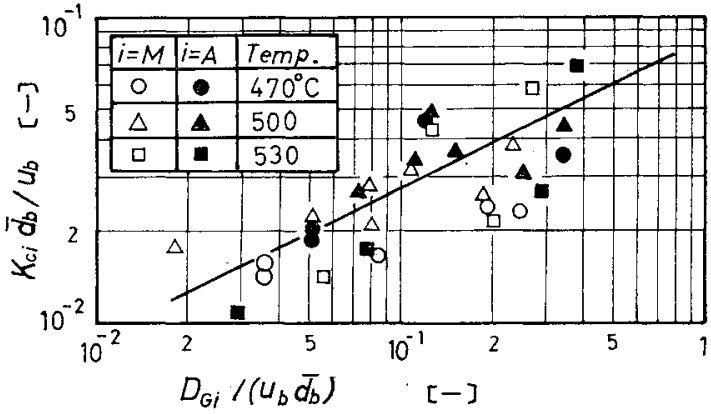

Fig. 10 Plot of $\left(K_{c i} \overline{d_{b}}\right) / u_{b}$ vs. $D_{G i} /\left(u_{b} d_{b}\right)$

binary $\mathrm{N}_{2}$-component $i$ system and was estimated according to Reid and Sherwood ${ }^{15)}$.

From the plots of $\left(K_{c i} \bar{d}_{b}\right) / u_{b}$ vs. $D_{G i} /\left(u_{b} \bar{d}_{b}\right)$ in Fig. 10, the values of $m, \beta_{M}$ and $\beta_{A}$ in Eq. (44) were $0.5,0.088$ and 0.088 , respectively. The evaluated value of $\delta_{w}$ showed in $0.43-0.55$ and its average value of $\hat{\delta}_{w}$ was 0.53 . In Figs. 5-7, the solid lines represent the curves calculated using these parameters.

\section{Discussion of the Results}

\section{1 Relation between bed expansion and bubble size}

An estimation of $\varepsilon_{b}$ based on the two-phase model has been made by Orcutt et al. ${ }^{13)}$, Davidson and Harrison ${ }^{1)}$, Kato and Wen ${ }^{7}$. Orcutt et al. ${ }^{13)}$ evaluated an effective bubble size by the following relation.

$$
\varepsilon_{b}=\frac{u_{o}-u_{m f}}{u_{0}-u_{m f}+0.711 \sqrt{g \bar{d}_{b}}}
$$

Kato and Wen ${ }^{7)}$ confirmed that Eq.(46) may be applied for the bed expansion data published by numerous workers. However, Toei et al. ${ }^{22)}$ reported that the rising velocity of bubbles varied along bed height. Godart et al. ${ }^{4}$ ) found that the rising velocity of many bubbles is many times greater than that of a single isolated bubble. In the present data relating to bed expansion, the $\varepsilon_{b}$ values calculated from Eq. (46) deviated from those observed at lower flow rate of gas and lower bed height. It was found in the present work that there existed many bubbles of fine size, less than 2-3 $\mathrm{mm}$ diameter, in the neighborhood of the gas distributor. On the other hand, Geldert et al. ${ }^{3)}$ reported that the voidage in the dense phase was quite large compared with that of the incipiently fluidized bed at low gas flow rates. Furthermore, the solid flow may be influenced by an electrostatic effect and wall effect. It may therefore be considered that Eq. (46) is not always applicable to estimate the bed expansion from operating conditions.

\section{2 Availability of simulation model}

The evaluated values of $K_{c M}$ and $K_{c A}$ using a simulation model for $\mathrm{MCH}$ cracking lay in less than about one to ten times those calculated from the empirical formula published in the literature ${ }^{1,10)}$. Despite numerous studies of the transport properties of the fluidized bed, little is known concerning these proper-

\begin{tabular}{|c|c|c|c|c|c|}
\hline \multicolumn{6}{|c|}{$\begin{array}{l}\text { Table } 4 \text { Comparison of solutions between rigorous } \\
\text { and simplified model }(\theta=4 \mathrm{~min} \text {. })\end{array}$} \\
\hline Run & $u_{o} / u_{m f}$ & & $\underset{[*]}{\mathrm{MCH}}$ & $\begin{array}{l}\text { Olefins } \\
{\left[{ }^{*}\right]}\end{array}$ & $\begin{array}{l}\text { Paraffins } \\
{[*]}\end{array}$ \\
\hline \multirow[t]{2}{*}{11} & 3.47 & R: & 0.40 & 0.039 & 0.082 \\
\hline & & S: & 0.40 & 0.034 & 0.087 \\
\hline \multirow[t]{2}{*}{10} & 3.47 & R: & 0.23 & 0.039 & 0.114 \\
\hline & & S: & 0.25 & 0.032 & 0.117 \\
\hline \multirow[t]{2}{*}{9} & 3.47 & $\mathrm{R}$ : & 0.17 & 0.030 & 0.136 \\
\hline & & S: & 0.17 & 0.032 & 0.140 \\
\hline \multirow[t]{2}{*}{12} & 4.06 & $\mathrm{R}:$ & 0.60 & 0.027 & 0.053 \\
\hline & & S: & 0.59 & 0.020 & 0.060 \\
\hline \multirow[t]{2}{*}{13} & 4.06 & $\mathrm{R}$ : & 0.63 & 0.018 & 0.090 \\
\hline & & S: & 0.59 & 0.018 & 0.091 \\
\hline \multicolumn{6}{|c|}{$[*]: \quad[g-c o m p o n e n t / g-f e e d]$} \\
\hline \multicolumn{6}{|c|}{$\begin{array}{ll}{[*]:} & \text { [g-component/g-teed }] \\
\text { R: } & \text { rigorous solution }\left(u_{e} \neq 0\right), \delta u\end{array}$} \\
\hline \multicolumn{6}{|c|}{ imnlified solution $(4=-0)$} \\
\hline
\end{tabular}

ties at high temperature ${ }^{12)}$. In addition, the behavior of fluidized bed involving chemical reaction may show complicating features. Shaw et al. ${ }^{17)}$ reported according to the Orcutt model ${ }^{13)}$ that the calculated selectivity in $n$-butane hydrogenolysis deviated from observations because of the reaction kinetics involving desorption and surface reaction. Partridge and Rowe ${ }^{14)}$ pointed out that the reaction performance of largesize solids was much more effective than that of small size. Hovmand and Davidson ${ }^{6}$ ) also reported that the estimated performance of an ozone decomposition deviated from observations with increasing reaction rate. From the facts above-mentioned, it was considered that the gas interchange coefficient showed a low value apparently because various factors such as size of solids ${ }^{14)}$, order of reaction rate $^{6)}$, adsorption/desorption of reactants on the catalyst ${ }^{18,19)}$, a lack of reactant in the dense phase ${ }^{18)}$, etc. However, the parameters calculated from Eq. (44) were useful in predicting the conversion and selectivity of $\mathrm{MCH}$ cracking in the fluidized-bed reactor.

On the other hand, the authors assumed the gas velocity in the dense phase as zero to formulate the simplified model as described previously. For the operating conditions of gas flow at which $u_{e} \neq 0$ according to Eq.(33), Eqs.(17)-(22) were resolved numerically according to the Runge-Kutta-Gill method to obtain rigorous predictions for the conversion and selectivity, and the calculated results are shown in Table 4. The predictions from the simplified model solution almost agreed with those of the rigorous solutions. This indicates that the simplified model is adequate to predict the fluidized-bed performance of MCH cracking.

\section{Conclusion}

The catalytic cracking of MCH was carried out using silica alumina catalyst in a fluidized bed, and the bubble size and bed expansion were measured. The product distribution was influenced by the bed height, flow rate and catalyst activity. A simulation model is proposed from the observation of bubble behavior, in a 
form which can predict the conversion and selectivity with catalyst fouling. Applying the model to experimental data, unknown parameters $\left(K_{c M}, K_{c A}, \delta_{w}\right)$ have been estimated by non-linear regression technique and have been rearranged with operating conditions. The present model is effective in simulating the performance of $\mathrm{MCH}$ cracking in a fluidized-bed reactor.

\section{Acknowledgment}

The authors express their gratitude for the helpfulness of Mr. M. Kawashima, who carried out the measurement of bed expansion and bubble size in a fluidized bed reactor.

\section{Nomenclature}

\begin{tabular}{|c|c|c|c|}
\hline$C_{i e}$ & \multirow{2}{*}{\multicolumn{3}{|c|}{$\begin{aligned}= & \text { weight fraction of component } i \text { in the bubble } \\
& \text { phase }(i=M, A, B) \quad \text { [g-component/g-feed MCH] } \\
= & \text { weight fraction of component } i \text { in the dense } \\
& \text { phase }(i=M, A, B) \quad \text { [g-component } / g \text {-feed MCH] }\end{aligned}$}} \\
\hline$C_{i e}$ & & & \\
\hline$D_{T}$ & $=$ & bed diameter & \\
\hline$f_{M}$ & $=$ & feed rate of methylcyclohexane & {$[\mathrm{g} / \mathrm{min}$} \\
\hline$g$ & $=$ & acceleration of gravity & {$\left[\mathrm{cm} / \mathrm{sec}^{2}\right.$} \\
\hline$K_{c i}$ & & $\begin{array}{l}\text { gas interchange coefficient of component } \\
i \text { between bubble phase and dense phase } \\
(i=M, A, B)\end{array}$ & {$\left[\sec ^{-1}\right]$} \\
\hline$k_{j}$ & $=$ & reaction rate constant for a fixed bed & {$\left[\sec ^{-1}\right.$} \\
\hline$k_{r j}$ & & $\begin{array}{l}\text { rate constant based on volume of solid } \\
(j=1,2,3,4,5, M) k_{r j}=k_{j} /\left(1-\varepsilon_{c}\right)\end{array}$ & {$\left[\sec ^{-1}\right]$} \\
\hline$L_{c}$ & $=$ & static bed height & \\
\hline$L_{f}$ & $=$ & bed height of a fluidized bed & \\
\hline$n_{c}$ & $=$ & coke content on catalyst & coke/g-ca \\
\hline$R$ & & gas constant $=1.987$ & $\mathrm{~g}-\mathrm{mol} \cdot{ }^{\circ} \mathrm{K}$ \\
\hline$T$ & $=$ & absolute temperature & {$\left[{ }^{\circ} \mathrm{K}\right.$} \\
\hline$u_{b}$ & $=$ & velocity of bubble rising through a bed & {$[\mathrm{cm} / \mathrm{sec}$} \\
\hline$u_{o}$ & & $\begin{array}{l}\text { superficial gas velocity based on } \\
\text { empty bed }\end{array}$ & {$[\mathrm{cm} / \mathrm{see}]$} \\
\hline$W$ & $=$ & weight of catalyst & \\
\hline$\alpha$ & $=$ & a constant as expressed in Eq. (9) [g-cat & $\mathrm{mg}$-coke \\
\hline$\gamma e$ & & $\begin{array}{l}\text { ratio of solid in the cloud-wake to volume } \\
\text { of bubbles in the bed }\end{array}$ & \\
\hline$\gamma e$ & & $\begin{array}{l}\text { ratio of solid in the dense phase to } \\
\text { volume of bubbles in the bed }\end{array}$ & \\
\hline$c$ & & voidage in a packed bed $=0.452$ & \\
\hline
\end{tabular}

\section{Literature Cited}

1) Davidson, J. F. and D. Harrison: "Fluidization", Academic Press, London and New York (1971)

2) Fryer, C. and O. E. Potter: Ind. Eng. Chem., Fundamentals, 11, 338 (1972)

3) Geldart, D. and R. R. Cranfield: Chem. Eng. J., 3, 21 I (1972)

4) Godart, K. and F. Richardson: Chem. Eng. Sci., 24, 663 (1969)

5) Higbie, R.: Trans. AIChE., 31, 365 (1935)

6) Hovmand, S. and J. F. Davidson: Trans. Instn. Chem. Engrs., 46, T190 (1968)

7) Kato, K. and C. Y. Wen: Chem. Eng. Sci., 24, 1351 (1969)

8) Kobayashi, H., F. Arai and T. Chiba: Kagaku Koggaku (Chem. Eng., Japan), 29, 858 (1965)

9) Kobayashi, H. and F. Arai: ibid., 29, 885 (1965)

10) Kunii, D. and O. Levenspiel: Ind. Eng. Chem., Fundamentals, 7, 446 (1968)

11) Kunii, D. and O. Levenspiel: Ind. Eng. Chem., Process Design and Develop., 7, 481 (1968)

12) Mii, T., K. Yoshida and D. Kunii: J. Chem. Eng. Japan, 6, $100(1973)$

13) Orcutt, J. C., J. F. Davidson and R. L. Pigford: Chem. Eng. Progr. Symp. Ser., 58(38), 1 (1962)

14) Partridge, B. A. and P. N. Rowe: Trans. Instn. Chem. Engrs., 44, T335 (1966)

15) Reid, R. C. and T. K. Sherwood: "Properties of Gases and Liquids", p. 543, McGraw-Hill, New York (1958)

16) Rowe, P. N., B. A. Partridge and E. Lyall: Chem. Eng. Sci., 19, 973 (1964)

17) Rowe, P. N. and B. A. Partridge: Trans. Instn. Chem. Engrs., 43, T157 (1965)

18) Shaw, I. D., T. W. Hoffman, A. Orlickas and P. M. Reilly: Can. J. Chem. Eng., 50, 637 (1972)

19) Swaaij, W. P. M. and F. J. Zuiderweg: "Chemical Reaction Engineering", p. B9-25, Elsevier Publishing Company, Amsterdam, London, New York (1972)

20) Sobol, M.: I. B. M. Share Program No. 1551, New York University Scoop Linear Surface Minimization Routine (1963)

21) Talmor, E. and R.F. Benenati: AIChE. J., 9, 536 (1963)

22) Toei, R., R. Matsuno, H. Kojima, Y. Nagai and S. Yu: Kagaku Kōgaku (Chem. Eng., Japan), 29, 851 (1965)

23) Tone, S., H. Seko, Y. Yokota and T. Otake: Bull. Japan Petrol. Inst., 13, 39 (1971) 